\title{
VARIABILIDADE ESPACIAL DE ATRIBUTOS FÍSICOS DO SOLO EM ÁREA DE ENCOSTA SOB PROCESSO DE DEGRADAÇÃ̃ ${ }^{1}$
}

\author{
FRANCIEZER VICENTE DE LIMA ${ }^{2 *}$, GUTTEMBERG DA SILVA SILVINO ${ }^{3}$, RICHARDSON SOARES DE SOUZA \\ MELO $^{2}$, ELDER CUNHA LIRA ${ }^{2}$, THIAGO DE SOUZA RIBEIRO ${ }^{2}$
}

\begin{abstract}
RESUMO - As condições físicas do solo são diretamente relacionadas com as práticas de manejo e o formato do relevo. A falta de manejo adequado pode levar os solos a processos erosivos e consequentemente degradação dessas áreas. Atualmente, estudos de variabilidade espacial permitem obter uma melhor análise para tomada de decisões e resoluções das referidas problemáticas. Pensando nisso, o presente estudo teve como objetivo avaliar a variabilidade espacial da infiltração de água no solo, densidade do solo e textura em área de encosta sobre processo de degradação. A pesquisa foi realizada em área de encosta com cultivo de pastagem, localizada entre os municípios de Areia (PB) e Remígio (PB). O solo foi amostrado em grade com malha regular $(20 \times 20 \mathrm{~m})$ entre pontos amostrais, perfazendo um total de 49 pontos em duas profundidades $(0-10 \mathrm{~cm} ; 10-20$ $\mathrm{cm})$, totalizando 98 amostras. Para a análise da variabilidade espacial foi utilizado a geoestatística, por meio da análise semivariográfica, interpolação dos dados por krigagem e construção de mapas de isolinhas. Todos os atributos físicos analisados apresentaram dependência espacial, uma vez que nenhum deles mostrou efeito pepita puro. Pôde-se verificar através dos mapas que houve uma relação muito clara entre a infiltração e os demais atributos físicos do solo, observando essa correlação principalmente na parte superior sudoeste da encosta.
\end{abstract}

Palavras-chave: Geoestatística. Textura. Infiltração. Relevo.

\section{SPATIAL VARIABILITY OF SOIL PHYSICAL PROPERTIES IN THE HILLY AREA OF DEGRADATION PROCESS}

\begin{abstract}
The physical conditions of the soil are directly related to management practices and relief format. Lack of proper management can lead to soil erosion and consequent degradation of these areas. Currently, studies of spatial variability analysis to enable better decisions and resolutions of such problems. The present study aimed to evaluate the spatial variability of soil water infiltration, soil density and texture in the hilly area of the degradation process. The survey was conducted in the hilly area cultivated with grassland, located between Areia and Remigio, two towns from Paraíba state. The soil was sampled at the regular grid with mesh $(20 \times 20 \mathrm{~m})$ between sample points, making a total of 49 points, into two depths, $0-10 \mathrm{~cm}, 10-20 \mathrm{~cm}$, totaling 98 samples. The analyze of spatial variability was doing by semivariogram geostatistical analysis, with data interpolation by kriging and make maps. All of them physical attributes analyzed presents spatial dependence since no one showed pure nugget effect. It was verified through the maps that there was a very clear relationship between infiltration and other soil physical characteristics, observing this correlation mainly in the upper southwest slope.
\end{abstract}

Keywords: Geostatistics. Texture. Infiltration. Relief

\footnotetext{
*Autor para correspondência

${ }^{1}$ Recebido para publicação em 06/05/2014; aceito em 22/05/2015

Parte da Dissertação de Mestrado do primeiro autor.

${ }^{2}$ Alunos de Pós-Graduação em Ciência do Solo, Universidade Federal da Paraíba, UFPB, Centro de Ciências Agrárias, CCA, Departamento de Solos e Engenharia Rural, DSER, Rodovia PB-079, km 12, CEP: 58.397-000. Areia (PB); franciezer@hotmail.com, richardsonsoares@hotmail.com, elder.lira@hotmail.com,thiago.sz31@ig.com.br.

${ }^{3}$ Professor Adjunto, Universidade Federal da Paraíba, UFPB, Centro de Ciências Agrárias, CCA, Departamento de Solos e Engenharia Rural, DSER, Rodovia PB-079, km 12, CEP: 58.397-000. Areia (PB); guttemberg@cca.ufpb.br.
} 


\section{INTRODUÇÃO}

Os solos localizados em áreas de encosta possuem características peculiares devido a sua forma de relevo, são resultantes dos processos de formação, como também advindos de práticas agrícolas. As superfícies que compõem o relevo exercem influência na exposição do material de origem, no sentido do fluxo da água no perfil do solo, na intensidade e ocorrência dos processos de erosão e lixiviação (ARTUR et al., 2014). Isto traz alterações nos atributos químicos, físicos e biológicos, acarretando efeitos sobre a qualidade ambiental da área (SOUZA et al., 2011). Assim, o estudo dessas áreas ajuda na tomada de decisões em relação ao manejo do solo, na intensidade e frequência de práticas agrícolas.

Souza et al. (2006) ressaltam que as alterações ocasionadas pelo relevo podem alterar a dinâmica hídrica nos solos de uma área, condicionando uma distribuição diferenciada de suas propriedades. Desta forma, a avaliação destes atributos auxilia no estudo do comportamento do solo em áreas degradadas e em recuperação. Dentre estes atributos podemos destacar a textura, a qual possui interferência direta nas demais propriedades físicas do solo, como na estrutura, distribuição de tamanhos de poros, compactação e adensamento, selamento superficial, escoamento superficial, drenagem e processo de infiltração (OLIVEIRA et al., 2013). A infiltração de água no solo pode ser considerada como um indicador da qualidade física por integrar fatores que diretamente afetam o desenvolvimento das plantas (JOSÉ et al., 2012).

Para uma adequada caracterização das propriedades do solo é importante considerar sua variabilidade espacial. Uma das formas de se analisar a variabilidade espacial das propriedades do solo é com o uso de geoestatística, uma ferramenta adequada e fundamental para a análise de propriedades que variem de um local para outro com algum grau de organização ou continuidade, expresso através da dependência espacial, de forma a obter conhecimento sobre a variabilidade das propriedades do solo, influenciando diretamente nos fatores de manejo e conservação dos solos (VIEIRA, 2000). Por essa razão, a caracterização da variabilidade espacial é essencial para um melhor entendimento das interrelações entre atributos do solo e o seu manejo.

Antoneli e Thomaz (2009) salientam que a alta variabilidade das propriedades físicas do solo, como o conteúdo de areia, argila e silte, e a densidade, resultam em alta variabilidade nas características de retenção de água pelo solo. Além das consequências para a conservação dos mesmos o adensamento e a baixa infiltração de água tornam as plantas mais suscetíveis a déficits hídricos e com limitada capacidade de absorver nutrientes em camadas subsuperficiais (BETIOLI JUNIOR et al., 2012). Nessa ótica, o presente estudo teve como objetivo avaliar a variabilidade espacial da infiltração, densidade do solo e textura em área de encosta sobre processo de degradação.

\section{MATERIAIS E MÉTODOS}

A pesquisa foi realizada em área de encosta pertencente a Fazenda Riachão, situada à margem da rodovia PB 079 entre os municípios de Areia (PB) e Remígio (PB). A mesma está inserida na microbacia hidrográfica Vaca-Brava, localizada na microrregião do Brejo paraibano, Nordeste do Brasil, compreendida entre as coordenadas geográficas $\mathrm{O} 35^{\circ} 46^{\prime}$ 13.648 " e S $6{ }^{\circ} 57$ ' 55.937".

Segundo a classificação de Köppen, predomina o clima do tipo As', o qual se caracteriza por ser quente e úmido, com chuvas de outono e inverno, estação seca podendo atingir entre cinco e seis meses e pluviosidade média anual entre 900 e $1.400 \mathrm{~mm}$. As temperaturas anuais apresentam máxima de $30^{\circ} \mathrm{C}$, média de $24^{\circ} \mathrm{C}$ e mínima de $18^{\circ} \mathrm{C}$ (GALVÃO et al., 2005).

A área da encosta selecionada ocupa uma superfície de aproximadamente 2,0 ha, com altitude variando de 595 a 565 m (Figura 1). Na parte de maior altitude o relevo da encosta tem forma côncava e de maneira geral apresenta variação entre ondulado e forte ondulado, proporcionando uma declividade de $24,28 \%$, enquadrando-se como relevo forte ondulado (faixa de 20 a 45\%) de acordo com Santos et al. 2006.

Não existe uma classificação precisa da classe de solo da área estudada. Entretanto, os solos da bacia hidrográfica, na qual a área em estudo se encontra localizada, foram classificados de forma geral como ARGISSOLO Vermelho Amarelo, tendo ocorrência em menor proporção de outros tipos de solo como, por exemplos, NEOSSOLO Litólico, NEOSSOLO Regolítico e o LATOSSOLO Amarelo (BRASIL, 1972).

A vegetação da área é caracterizada predominantemente como pastagem, sendo composta principalmente pela gramínea Brachiaria decumbes. Segundo Galvão et al. (2005), a pecuária é uma das principais atividades econômicas da região. Dessa forma, a área em questão é explorada para alimentação de bovinos por quase todo o decorrer do ano.

Foram coletadas amostras de solo nas profundidades de 0-10 e 10-20 cm em 49 pontos georreferenciados, obedecendo uma malha regular de $20 \times 20$ metros, totalizando 98 amostras, que foram secas ao ar, destorroadas, passadas em peneiras de malha de 2 mm para obtenção da terra fina seca ao ar (TFSA) e analisadas quanto às propriedades granulométricas (areia, silte e argila). Antes da passagem do solo para pulverização na peneira foram retirados torrões para análise da densidade do solo, cujos procedimentos foram realizados no Laboratório de Física do Solo DSER/CCA/UFPB, seguindo a metodologia adotada pela Embrapa (2009). 


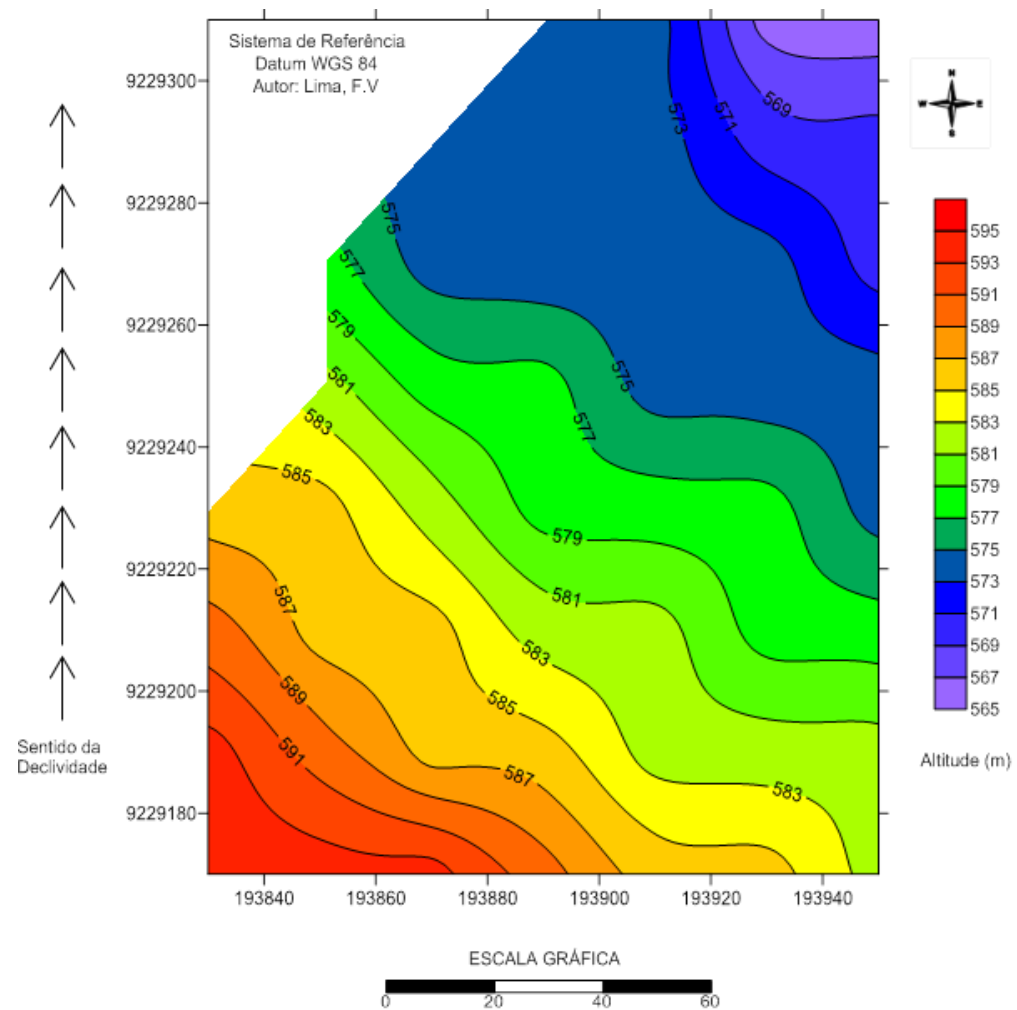

Figura 1. Mapa de isolinhas da altitude e sentido da declividade da área da encosta em estudo.

Ainda obedecendo à grade $(20 \times 20 \mathrm{~m})$ foram realizados testes de infiltração em todos os 49 pontos amostrais da área utilizando cilindros infiltrômetros, com altura de $15 \mathrm{~cm}$ e diâmetro de $15 \mathrm{~cm}$, conforme a metodologia de "Beerkan" descrita por Lassabatére et al. (2006) e Souza et al. (2008).

A variabilidade do solo foi inicialmente analisada pela estatística descritiva dos dados, calculandose os valores mínimo, máximo, média, mediana, desvio padrão, coeficiente de variação, coeficiente de assimetria e coeficiente de curtose. Também foi realizada análise de normalidade através do teste de Shapiro-Wilks (w) feita através do software Assitat (SILVA; AZEVEDO, 2002). A avaliação da variabilidade dos atributos foi baseada nos limites propostos por Warrick e Nielsen (1980) para a classificação de atributos do solo considerando-se: variabilidade baixa $(\mathrm{CV}<12 \%)$; média $(12 \%<\mathrm{CV}<60 \%)$; e alta $(\mathrm{CV}>60 \%)$.

A análise geoestatística foi realizada pelo Software $\mathrm{GS}^{+}$(Gamma Design, 2004), os mapas construídos utilizando-se os pontos amostrais com suas respectivas coordenadas geográficas e atribuindo-se valores nos locais não amostrados através da técnica de Krigagem, e das estruturas de dependência espacial obtidas nos semivariogramas, após as análises, exportando-se as imagens para edição no programa computacional Surfer 9 (Golden software, 2010).

Posteriormente, fora utilizada a classificação de Cambardella et al. (1994), que define um parâmetro de comparação baseado no tamanho relativo do efeito pepita, chamado de grau de dependência espacial (GDE), o qual possibilita a comparação do tama- nho relativo do efeito pepita entre os atributos do solo dado pela equação:

$$
\mathrm{GDE}=\frac{\mathrm{y}(\mathrm{h}) \text { pepita }}{\mathrm{y}(\mathrm{h}) \text { total }} \times 100
$$

Onde GDE - Grau de dependência espacial, $\gamma$ (h) pepita - semivariância do efeito pepita e $\gamma(\mathrm{h})$ total - semivariância total ou patamar. $\mathrm{O}$ aplicativo $\mathrm{GS}^{+}$ trabalha com a seguinte relação:

$\%$ Semivariancia estrutural $=\frac{\mathrm{C} 1}{\left(C_{1}+C_{0}\right)} \times 100$

Os resultados do GDE foram classificado da seguinte forma: dependência espacial forte $\leq 25 \%$; dependência espacial moderada entre $25 \%$ e $75 \%$; e dependência espacial fraca quando o efeito pepita é $>$ $75 \%$.

Os valores analíticos dos atributos físicos avaliados foram utilizados para a análise da variabilidade espacial, bem como seus graus de dependência espacial (GDE). Os modelos foram ajustados, considerando-se individualmente cada atributo e também o conjunto de dados que representam cada profundidade de solo, utilizando os procedimentos geoestatísticos, considerando-se as análises semivariográficas isotrópicas.

\section{RESULTADOS E DISCUSSÃO}

A Tabela 1 apresenta os resultados da análise estatística descritiva para a taxa de infiltração, densidade do solo, areia, silte e argila nas camadas de 0 - 
10 e 10-20 cm. Os valores da média e da mediana para os atributos estão próximos, indicando que estes dados seguem uma distribuição simétrica. Segundo Cambardella et al. (1994), os valores da média sendo próximos daqueles da mediana é um indicativo de que as medidas de tendência central são dominadas por valores típicos na distribuição. De maneira geral, os dados da Tabela 1 mostram tendência à menor distorção e maior normalidade, na qual a maioria dos atributos apresentou distribuição normal pelo teste Shapiro-Wilks (W). Valores similares foram encontrados por Campos et al. (2013), estudando a variabilidade espacial de atributos físicos do solo.

Tabela 1. Análise descritiva dos atributos do solo: Taxa de infiltração $\left(\mathrm{mm} \mathrm{h}^{-1}\right)$; Densidade do solo $\left(\mathrm{g} \mathrm{cm}^{3}\right) ; \operatorname{Areia}\left(\mathrm{g} \mathrm{kg}^{-1}\right)$; Silte $\left(\mathrm{g} \mathrm{kg}^{-1}\right)$; e Argila $\left(\mathrm{g} \mathrm{kg}^{-1}\right)$ nas camadas de 0-10 e 10-20 cm.

\begin{tabular}{|c|c|c|c|c|c|c|c|c|c|}
\hline Variáveis & Min & Max & Med & Mediana & $\mathrm{DP}$ & $\mathrm{CV}(\%)$ & As & Curt & $\mathrm{W}^{*}$ \\
\hline \multicolumn{10}{|c|}{ Infiltração } \\
\hline T. Inf. & 1059 & 9139 & 3887 & 3828 & 2014 & 45 & 1,04 & 0,33 & Não \\
\hline \multicolumn{10}{|c|}{ Profundidade $0-10 \mathrm{~cm}$} \\
\hline Ds $0-10$ & 1,46 & 1,7 & 1,6 & 1,65 & 0,05 & 3 & $-0,92$ & 0,63 & Sim \\
\hline Ar $0-10$ & 584 & 913 & 787 & 781 & 70,86 & 9 & $-0,35$ & 0,04 & Sim \\
\hline S $0-10$ & 28 & 130 & 75 & 72 & 24,78 & 33 & 0,31 & $-0,59$ & Sim \\
\hline Ag 0-10 & 48 & 325 & 137 & 133 & 59,80 & 43 & 0,71 & 0,57 & Sim \\
\hline \multicolumn{10}{|c|}{ Profundidade $10-20 \mathrm{~cm}$} \\
\hline Ds $10-20$ & 1,48 & 1,7 & 1,5 & 1,6 & 0,05 & 3 & $-0,45$ & 0,01 & Sim \\
\hline Ar $10-20$ & 614 & 897 & 760 & 755 & 81,18 & 11 & $-0,09$ & $-1,23$ & Não \\
\hline S $10-20$ & 25 & 175 & 71 & 68 & 29,68 & 40 & 0,97 & 1,88 & Não \\
\hline Ag 10-20 & 60 & 292 & 165 & 159 & 68,74 & 41 & 0,19 & $-1,30$ & Não \\
\hline
\end{tabular}

Min: valor mínimo; Max: valor máximo; Med: valor médio; DP: desvio padrão; CV: coeficiente de variação; As: assimetria; Curt: curtose; *: teste de normalidade Shapiro-Wilks (5\% de significância); T. inf: taxa de infiltração; Ds: densidade do solo; Ar: areia; S: silte; e Ag: argila.

Os coeficientes de assimetria e curtose indicam se a distribuição dos dados de uma variável está próxima à distribuição normal (coeficientes iguais à zero) (CAMPOS et al., 2012). Apesar da normalidade dos dados não ser uma exigência da geoestatística, o importante é que a distribuição não se apresente muito alongada, o que poderia comprometer as estimativas da krigagem, as quais são baseadas nos valores médios.

Com base no critério de Warrick e Nielsen (1980), para classificar o coeficiente de variação (CV) foram verificados os valores médios para as variáveis taxa de infiltração, silte e argila nas duas camadas estudadas, com exceção da densidade do solo e areia, que apresentaram coeficiente de variação classificado como baixo em ambas as profundidades amostrais. O CV pode ser usado para comparar e avaliar as variáveis, podendo-se observar que as variáveis que apresentam um $\mathrm{CV}$ baixo indicam uma pequena variação dos dados em relação a média, mostrando uma distribuição homogênea.

A Tabela 2 apresenta os resultados dos parâmetros geoestatísticos dos dados analisados. Pode-se observar que os dados dos atributos físicos estudados ajustaram-se adequadamente aos modelos matemáticos gausiano, esférico e exponencial. Apesar do modelo esférico ser considerado por muitos autores como o que melhor se ajusta aos atributos do solo (SIQUEIRA et al., 2008; GUEDES FILHO et al., 2010), para as variáveis estudadas o modelo de semivariograma que se sobressaiu foi o gaussiano, seguido do esférico e sequencialmente o exponencial (Tabela 2).

Tabela 2. Modelos e parâmetros estimados dos semivariogramas experimentais para os dados de Taxa de infiltração $\left(\mathrm{mm} \mathrm{h}^{-1}\right)$, Densidade do solo $\left(\mathrm{g} \mathrm{cm}^{3}\right)$, Areia $\left(\mathrm{g} \mathrm{kg}^{-1}\right)$, Silte $\left(\mathrm{g} \mathrm{kg}^{-1}\right)$ e Argila $\left(\mathrm{g} \mathrm{kg}^{-1}\right)$ nas camadas de 0-10 e $10-20 \mathrm{~cm}$.

\begin{tabular}{|c|c|c|c|c|c|c|c|}
\hline Variáveis & Modelo & $\mathrm{R}^{2}$ & Ef Pepita $\left(\mathrm{C}_{0}\right)$ & $\begin{array}{c}\text { Patamar } \\
\mathrm{C}_{1}\end{array}$ & $\mathrm{C}_{0} /\left(\mathrm{C}_{0}+\mathrm{C}_{1}\right)$ & Alcance $\left(\mathrm{A}_{0}\right)$ & GDE \\
\hline \multicolumn{8}{|c|}{ Infiltração } \\
\hline T. Inf. & Gausiano & 0,99 & 763464 & 641000 & 88 & 156,92 & Fraca \\
\hline \multicolumn{8}{|c|}{ Profundidade $0-10 \mathrm{~cm}$} \\
\hline Ds $0-10$ & Exponencial & 0,50 & 35 & 483 & 73 & 18,20 & Moderado \\
\hline Ar $0-10$ & Esférico & 0,99 & 780 & 6004 & 87 & 111,70 & Fraca \\
\hline S $0-10$ & Gausiano & 0,38 & 76 & 781 & 90 & 32,90 & Fraca \\
\hline Ag $0-10$ & Gausiano & 0,99 & 1280 & 5348 & 76 & 124,53 & Fraca \\
\hline \multicolumn{8}{|c|}{ Profundidade $10-20 \mathrm{~cm}$} \\
\hline Ds $10-20$ & Esférico & 0,58 & 0,0 & 0,0242 & 71 & 25,90 & Moderado \\
\hline Ar $10-20$ & Gausiano & 0,99 & 2460 & 8514 & 71 & 120,55 & Moderado \\
\hline S $10-20$ & Esférico & 0,15 & 42 & 943 & 95 & 35,80 & Fraca \\
\hline Ag $10-20$ & Gausiano & 0,99 & 1530 & 6719 & 77 & 125,57 & Fraca \\
\hline
\end{tabular}

$\mathrm{R}^{2}$ : Coeficiente de determinação; Ef pepita: efeito pepita; $\mathrm{C}_{0} /\left(\mathrm{C}_{0}+\mathrm{C}_{1}\right)$ : Dependência espacial; GDE: Grau de dependência espacial; T. inf: taxa de infiltração; Ds: densidade do solo; Ar: areia; S: silte; e Ag: argila. 
Observa-se que todos os atributos físicos do solo apresentaram dependência espacial, uma vez que nenhum apresentou efeito pepita puro. A maioria dos parâmetros se enquadrou com GDE fraco, mas a densidade do solo se apresentou como moderada nas duas profundidades, assim como areia $(10-20 \mathrm{~cm})$. Cambardella et al. (1994) evidenciam que quanto mais fortemente for a dependência espacial maior será a possibilidade de se afirmar que uma variável é influenciada pelas propriedades intrínsecas do solo, como a densidade, porosidade, teor de água etc. Já os atributos com depêndencia fraca são mais influenciadas por fatores extrinsecos ou externos, como o relevo, o manejo do solo, o pisoteio animal etc.

Os atributos que apresentaram um GDE considerado moderado, de acordo com a classificação adotada neste trabalho, mostra que eles sofrem muito mais influências ocasionadas pelo relevo, falta de manejo e pisoteio animal do que os demais.

A dependência existente entre os pontos de uma área é quem vai permitir correlacionar o intervalo entre eles. No caso da área em estudo, o número total de 49 pontos em aproximadamente dois hectares permitiu fazer uma boa inferência sobre os atributos analisados, no qual, de acordo com os resultados encontrados na Tabela 2, verifica-se que a distância estabelecida de 20 metros entre os pontos foi adequada para verificar a relação existente no intervalo de espaço entre ambos, ou seja, foi possível perceber que a semelhança entre os pontos foi apropriada.

Outro fator que elucida a representatividade espacial da área e que está ligada a dependência é o alcance, o qual é referente a distância total de semelhança entre os pontos. Neste estudo foi possível verificar (Tabela 2) que para a grande maioria das variáveis analisadas a correlação existente entre os pontos foi muito além dos 20 metros, estabelecendose, com isso, que o intervalo entre os pontos poderia ter sido maior, o que serve de referência para trabalhos futuros na mesma área e até mesmo na região.

Diante disso, os maiores alcances encontrados foram para a taxa de infiltração $(156,92 \mathrm{~m})$, seguida da argila $(124,53$ e $125,57 \mathrm{~m})$ e areia $(111,70$ e $120,55 \mathrm{~m}$ ) nas duas profundidades $0-10 \mathrm{~cm}$ e $10-20$ $\mathrm{cm}$, respectivamente (Tabela 2). Essa observação indica que o número de amostras para as variáveis citadas poderiam ter sido menor, pois de acordo com Trangmar et al. (1985), o alcance estabelece o limite de dependência espacial entre as amostras, isto é, as distâncias até onde se pode afirmar que os valores vizinhos de uma variável estão espacialmente correlacionados, que neste estudo foi de 20 metros, e podem ser utilizados para se estimar valores em qualquer ponto entre eles. Os resultados corroboram com Carvalho et al. (2011), os quais trabalharam com a variabilidade espacial de atributos físicos de três classes de solos cultivados com cana-de-açúcar sob colheita mecanizada.
Esses resultados são importantes para o planejamento experimental da área estudada e devem ser levados em consideração em termos de proposta para seu manejo e posteriores pesquisas, assim como na determinação do número de pontos que devem ser amostrados para se obter uma melhor representatividade (CAMARGO et al., 2010). A análise da relação $\left[\mathrm{C}_{0} /\left(\mathrm{C}_{0}+\mathrm{C}_{1}\right)\right]$ mostrou que as variáveis em estudo apresentaram fraca dependência espacial, o que está de acordo com Campos et al. (2012), que também encontraram valores semelhantes em trabalho com variabilidade espacial de atributos físicos do solo em áreas cultivadas com mandioca.

Na Figura 2 está representado o mapa de isolinhas da taxa de infiltração, no qual é possível observar a disposição da mesma no solo da encosta. A ocorrência de pequenas áreas com concentrações de linhas de contorno fechadas sugerem o acontecimento de variações nos valores da taxa de infiltração, ou seja, ocorrência de flutuações nos valores em intervalo de espaço amostral, demostrando que na maioria dos pontos a taxa de infiltração se encontra no intervalo de 450 a $175 \mathrm{~mm} \mathrm{~h}^{-1}$, como também é possível verificar que a ocorrência das menores taxas de infiltração (150 a $\left.25 \mathrm{~mm} \mathrm{~h}^{-1}\right)$ são constatadas em pontos mais isolados, sendo eles representados pela cor mais avermelhada no mapa. Pode-se verificar também uma diferença nítida no comportamento da infiltração no solo da encosta, a qual praticamente faz uma divisão na área da mesma, representada pela cor azul, onde são encontrados os maiores valores de infiltração (325 a $450 \mathrm{~mm} \mathrm{~h}^{-1}$ ). Alguns autores ressaltam a ocorrência de variações da infiltração em pequeno espaço amostral (JOSÉ et al., 2012).

Verifica-se que na parte de maior altitude, e também com a presença de maior declividade da área (Figura 2), são encontrados os menores valores para a taxa de infiltração, demostrando a forte influência do relevo nesta variável e consequentemente na contribuição para o aumento da degradação da área. Sabe-se que os fatores de formação do solo (material de origem, clima, organismos, relevo e tempo) têm influência no resultado final dos solos e também que estes estão em operação constantemente. Entre esses fatores destacamos o relevo, considerado muito mais, como um agente de remoção e destruição do solo do que de formação, visto sua influência no processo erosivo.

O relevo com seus componentes recebem especial atenção, tendo destacada influência sobre a infiltração, movimentação vertical e horizontal de água. O estudo do relevo apresenta grande importância para os processos que envolvem o movimento e armazenamento de água dentro do perfil do solo e, ainda, sua relação com o transporte e a deposição de sedimentos, de maneira a causar variabilidade espacial nos atributos do solo. A textura também é uma característica que influencia diretamente a taxa de infiltração (BETIOLI JÚNIOR et al., 2012). Os solos 
arenosos apresentam maior quantidade de fina (argilosos) (SANTOS et al., 2012). macroporos do que propriamente os solos de textura

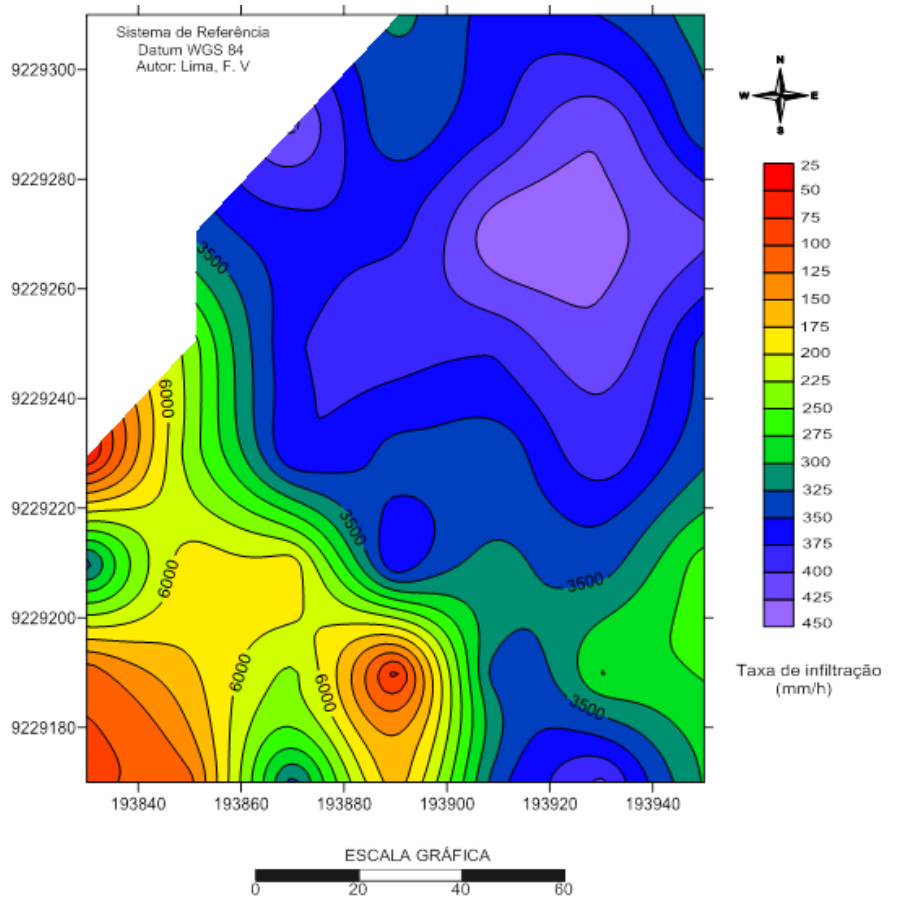

Figura 2. Mapa de isolinhas dos dados da taxa de infiltração $\left(\mathrm{mm} \mathrm{h}^{-1}\right)$ no solo de encosta.

Os mapas de densidade do solo (Figura 3) apresentam as mesmas conformidades observadas nos demais, expondo condições semelhantes em ambas as profundidades analisadas, em que os maiores valores estão presentes na parte de maior altitude da encosta, com valores de densidade do solo que variaram de 1,46 a $1,7 \mathrm{~g} \mathrm{~cm}^{-3}$ (Figura $3 \mathrm{~A}$ ), sendo que os valores mais altos $\left(1,62\right.$ a $\left.1,7 \mathrm{~g} \mathrm{~cm}^{-3}\right)$ foram encontrados desde o centro até a região de maior altitude

\section{A)}

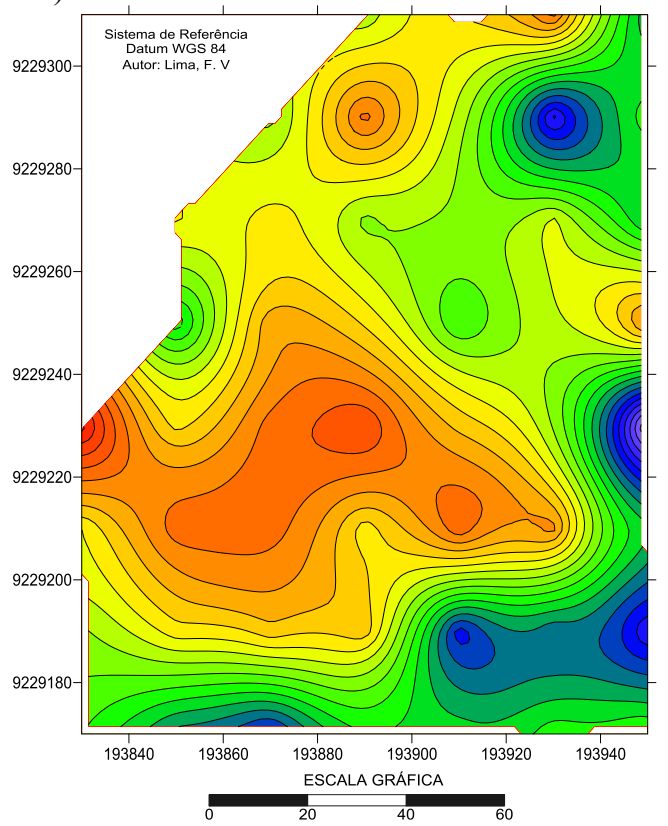

da área, seguindo a mesma conformação dos demais atributos analisados. Na Figura 3B, os maiores valores também estão seguindo a mesma tendência, apenas um pouco mais distribuídos pelo centro da encosta. Esses resultados podem ter relação com o número excessivo de bovinos caminhando sobre a área, que devido a uma taxa de lotação exagerada podem provocar sérios problemas na densidade do solo.

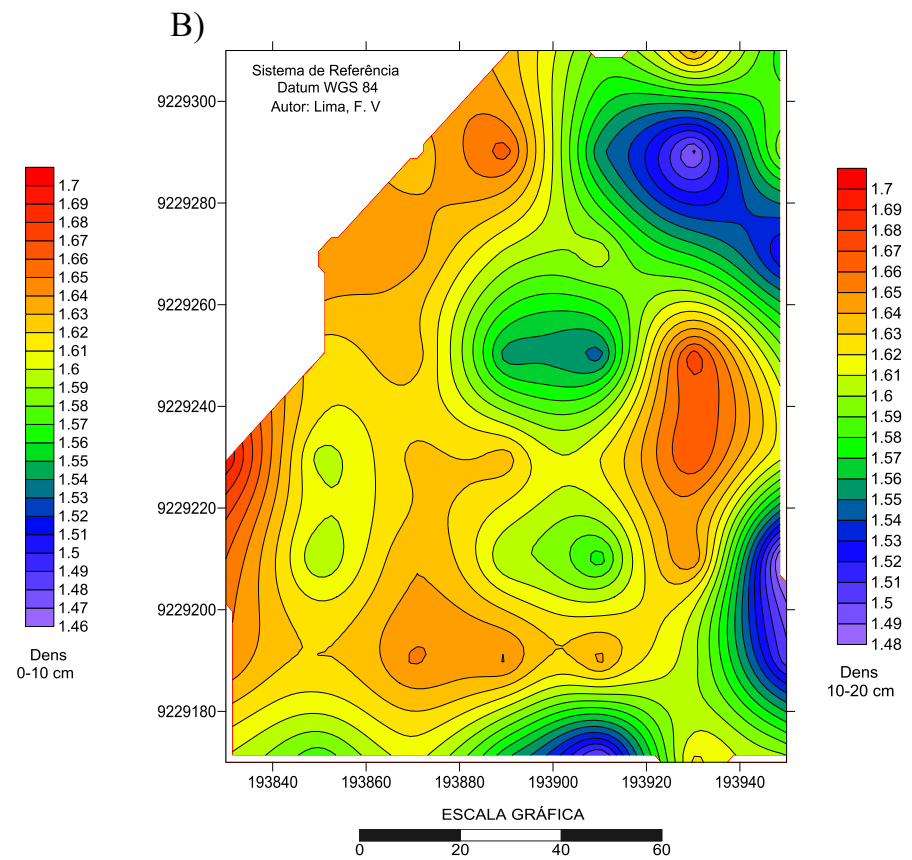

Figura 3. Mapa de isolinhas dos dados de densidade do solo no solo da encosta, A) $(0-10 \mathrm{~cm})$ e B) $(10-20 \mathrm{~cm})$, com valo-

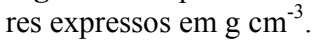

Revista Caatinga, Mossoró, v. 28, n. 4, p. 53 - 63, out. - dez., 2015 
Verificou-se que algumas partes da área apresentaram valores de densidade inadequados, com necessidade de adoção de um manejo apropriado, sugerindo-se uma combinação de práticas de manejo para retardar o problema de compactação do solo.

Segundo Mion et al. (2012), a densidade do solo é uma das propriedades físicas que podem caracterizar o estado de compactação, sendo limitantes ao crescimento radicular. No entanto, Siqueira et al. (2008) apontam que não há um consenso quanto ao valor crítico da densidade do solo.

$\mathrm{Na}$ Figura 4 verifica-se a distribuição dos teores de areia na área de estudo, relatando-se a gran-

A)

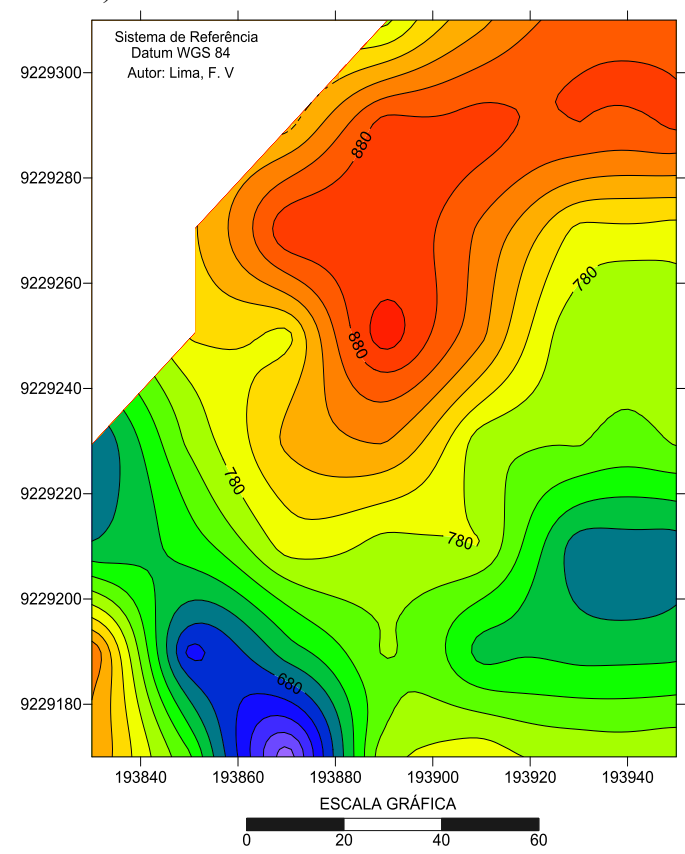

de ocorrência do atributo na camada de $0-10 \mathrm{~cm}$ (Figura 4A). Esse fato já era esperado, pois sabe-se que com o aumento da profundidade há uma diminuição nas quantidades de areia. Nota-se, também, que a maior concentração se dá na parte inferior da encosta, o que pode ser explicado pelo carreamento das partículas da parte superior. Na Figura 4B observa-se que na profundidade de $10-20 \mathrm{~cm}$ os teores de areia da parte superior são menores que os da parte inferior, destacado pela cor mais azulada na parte alta da encosta, cujos valores de areia partem de 610 para $890 \mathrm{~g} / \mathrm{kg}$, da parte superior para a inferior da encosta, respectivamente.

B)

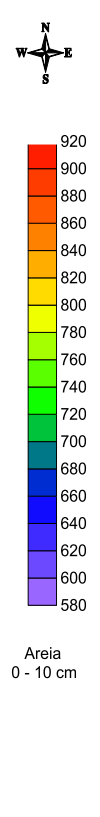

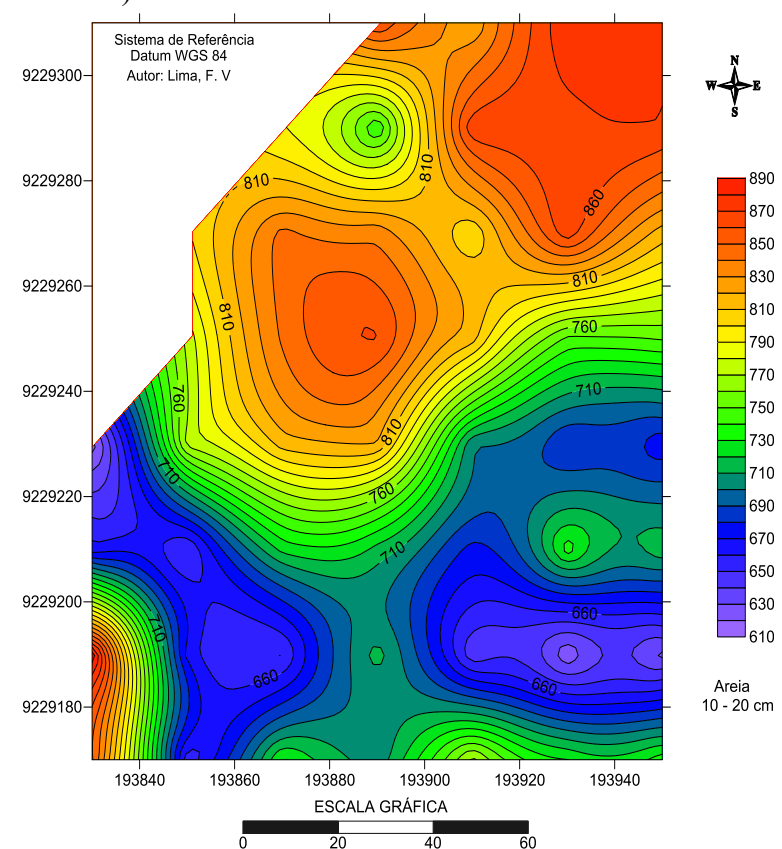

Figura 4. Mapa de isolinhas dos dados do atributo areia no solo da encosta, A) $(0-10 \mathrm{~cm})$ e B) $(10-20 \mathrm{~cm})$, com valores $\mathrm{em} \mathrm{g} / \mathrm{kg}$.

A parte inferior da encosta caracteriza uma região de recebimento de sedimentos de diferentes granulometrias. Por se tratar de uma área abaixo do ponto mais alto da encosta ainda sim está sujeita ao processo de remoção, desta vez de partículas mais finas, por se tratar de uma área mais plana em que a velocidade de enxurrada não chega a ser suficiente para dar continuidade à remoção de sedimentos mais grosseiros (areia), ficando esse material depositado no local.

Em relação ao atributo silte (Figura 5) é visualizado um rápido incremento quando comparado as duas profundidades, verificando-se que na profundi- dade de $0-10 \mathrm{~cm}$ (Figura 5A) os valores do atributo são menores em relação aos da profundidade 10-20 $\mathrm{cm}$ (Figura 5B). A fração silte apresenta variações no seu teor ao longo da encosta, visualizando-se pequenas manchas mais avermelhadas em ambas as profundidades, considerando-se que os teores de silte são maiores em profundidade (TAVARES et al., 2012), havendo assim áreas mais vermelhas em relação a camada superficial, sendo esta uma característica fundamental do atributo. Essa fração, em função de sua instabilidade, é pouco desejável, visto que é a primeira a se desprender pela ação das gotas de chuva, tornando-se a principal fração a ser arrastada. 
A)

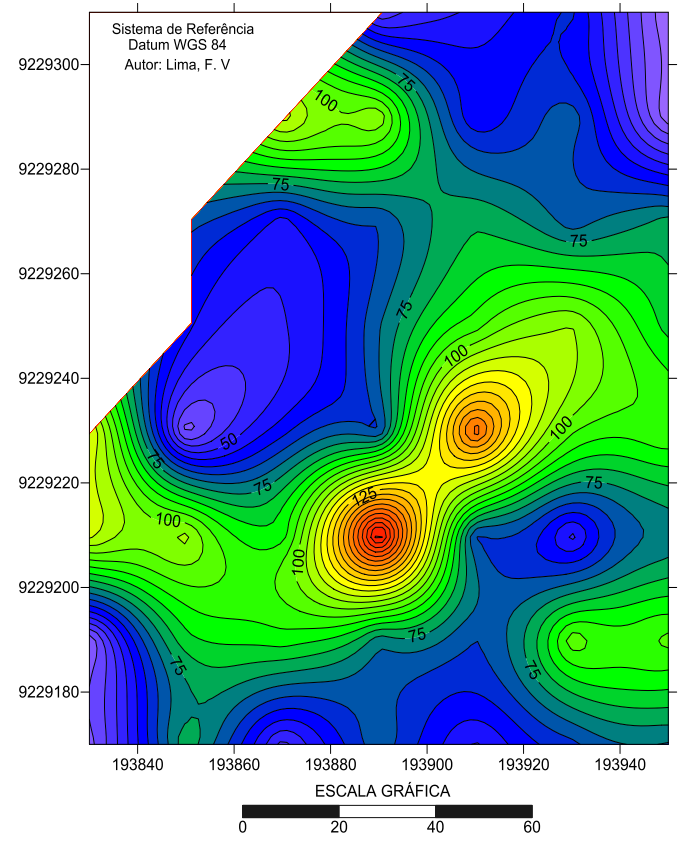

B)

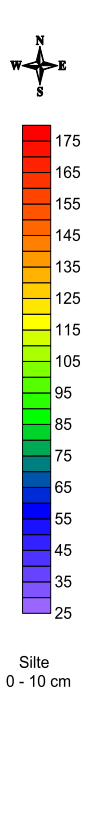

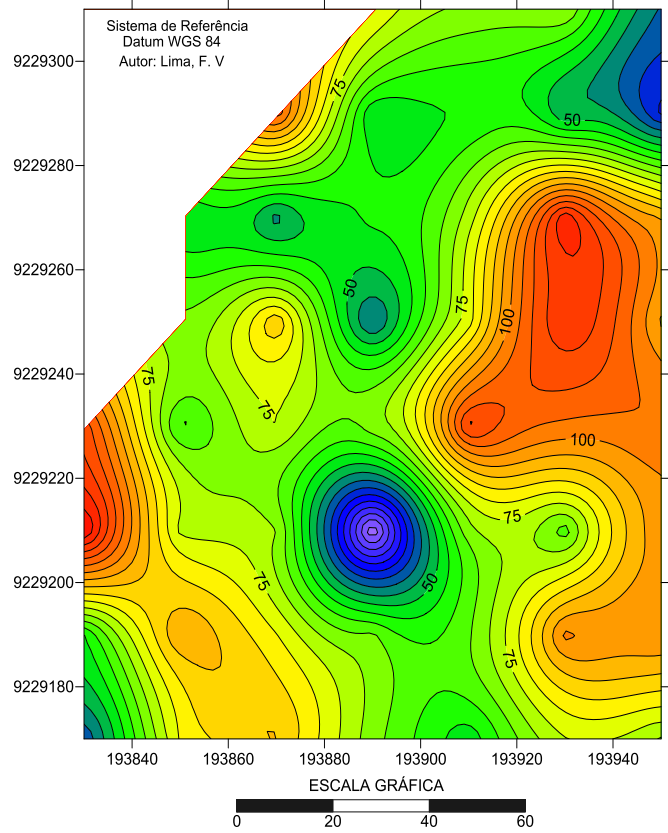

$\underset{s}{\tan }$

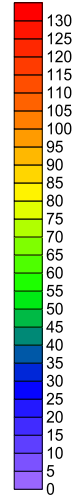

Silte $10.20 \mathrm{~cm}$

Figura 5. Mapa de isolinhas dos dados do atributo silte no solo da encosta, $A)(0-10 \mathrm{~cm})$ e B) $(10-20 \mathrm{~cm})$, com valores $\mathrm{em} \mathrm{g} / \mathrm{kg}$.

Tratando-se do atributo argila (Figura 6), verifica-se um comportamento inverso ao da areia, perceptível nas duas profundidades $0-10$ e $10-20 \mathrm{~cm}$ (Figura $6 \mathrm{~A}, \mathrm{~B}$ ), pois para o atributo areia os maiores valores foram encontrados na parte mais baixa da encosta, tendo ocorrido fato inverso para o atributo argila, onde os maiores valores estão justamente na parte superior, mostrando assim uma semelhança no padrão de variabilidade espacial entre as frações

A)

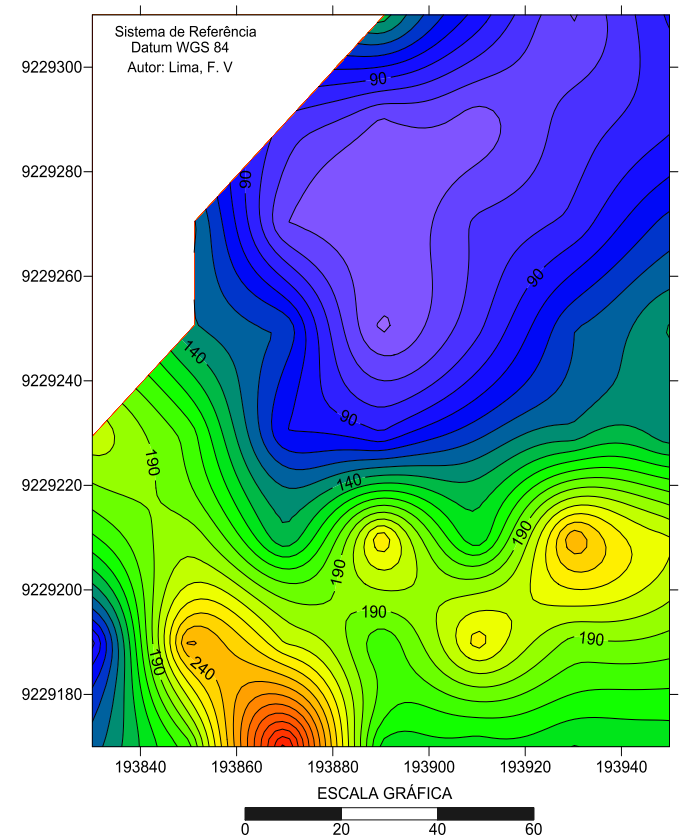

areia e argila. Todavia, nota-se magnitudes opostas, ou seja, as áreas de maiores teores de argila coincidem com as áreas de menores teores de areia, verificando-se a correlação negativa altamente significativa entre essas duas propriedades na área de estudo, cujos resultados concordam com Siqueira et al. (2008) ao trabalharem com a variabilidade de atributos físicos do solo determinados por diversos métodos.

B)

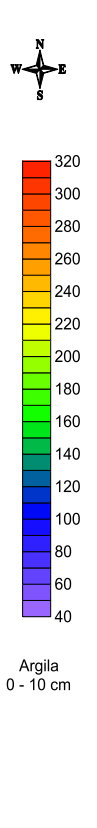

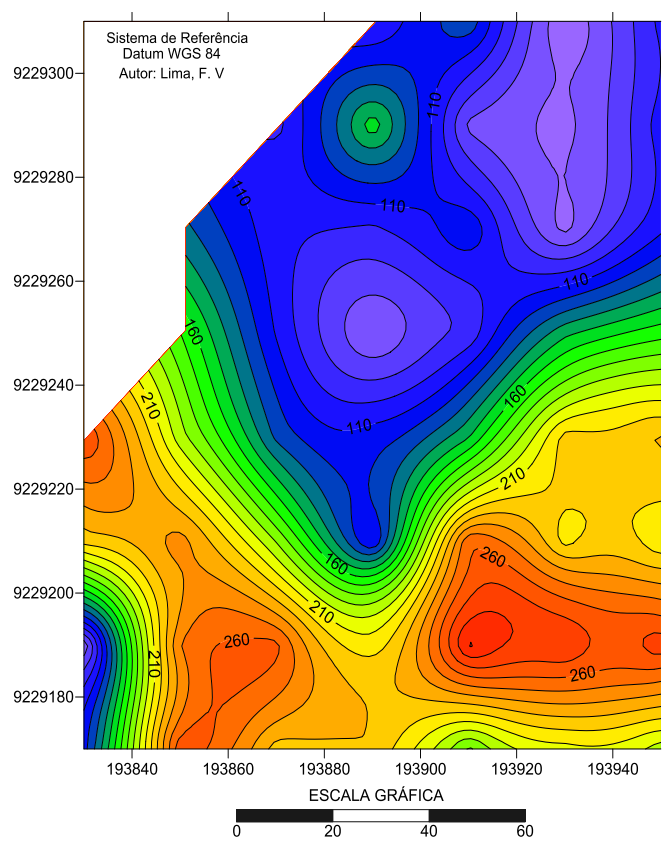
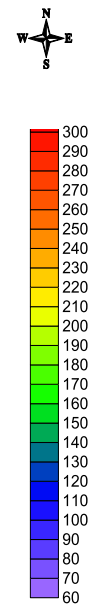

Argila
$10-20 \mathrm{~cm}$

Figura 6. Mapa de isolinhas dos dados do atributo argila no solo da encosta, A) $(0-10 \mathrm{~cm})$ e B) $(10-20 \mathrm{~cm})$, com valores $\mathrm{em} \mathrm{g} / \mathrm{kg}$. 
Tavares et al. (2012), utilizando funções geoestatísticas, observaram que há uma grande heterogeneidade entre os atributos físicos do solo, apesar da aparente semelhança visual. Um importante argumento a ser tomado como explicação para os problemas relacionados à degradação da área em função da perda de solo e ocorrência de erosão são os problemas ocasionados pelo relevo e o pisoteio animal (TORRES et al., 2012), os quais podem trazer consequências negativas para as propriedades físicas estudadas. Como a área em estudo é utilizada para o fim de alimentação animal conclui-se que esse tipo de exploração pode contribuir com alguns danos, ressaltando que a área estudada tem um histórico de aproximadamente 20 anos para pastoreio animal.

Fazendo-se uma correlação entre o mapa da taxa de infiltração (Figura 2) com os teores de areia (Figura 4) e os mapas de argila (Figura 6) detecta-se forte ligação existente entre esses atributos, bem como a influência da granulometria do solo no processo de infiltração, evidenciando que nos locais de maior infiltração são encontradas as maiores concentrações de areia e menores concentrações de argila, decorrente do maior arejamento proporcionado pelo arranjo físico das partículas de areia, o qual permite a melhor passagem de água, demostrando com isso a precisão da técnica geoestatística e da krigagem na confecção final dos mapas.

Ressalta-se que o comportamento espacial dos mapas foi semelhante em toda a área, no qual foram encontrados os maiores valores sempre na parte de maior altitude da encosta, afirmando que existe um comprometimento dessa área, muito provavelmente provocado pela junção do pisoteio dos animais, como também pela influência do relevo, tornando necessária a adoção de um manejo adequado a fim de minimizar os impactos causados.

Com a visualização da distribuição espacial dos atributos do solo nos mapas torna-se mais fácil proceder ao planejamento na tomada de decisão e manejos mais apropriados para a área. Por exemplo, de posse dos mapas é possível separar locais que precisam de maiores cuidados referente ao manejo, identificando as diferenças no solo para um mesmo atributo, no qual devem ser adotadas medidas que protejam o solo, como mantê-lo com cobertura mais densa e/ou adotando práticas conservacionistas como, por exemplos, terraços, cordões de isolamento entre outras (SANTOS et al., 2012).

Com os resultados, têm-se indicativos de uma distribuição das partículas granulométricas influenciada pelo relevo, que interligada ao movimento de água na superfície do solo provoca um deslocamento dessas partículas e que estas têm interferência direta no processo de infiltração.

Juntando os problemas causados pelo pisoteio animal com a intensificação do relevo, sendo este outro fator que ocasiona sérias mudanças na estrutura física do solo, a combinação desses, assim como a falta de um manejo adequado para áreas com confor- mação e esse tipo de uso é provável que ocorram problemas de degradação do solo, o que já se torna perceptível na encosta estudada, onde em muitos locais o solo já se encontra quase que completamente desnudo e também o surgimento de erosão, principalmente em áreas onde a declividade é maior.

\section{CONCLUSÕES}

O modelo de amostragem foi apropriado para a análise da variabilidade espacial dos respectivos atributos, taxa de infiltração, densidade do solo e textura, podendo afirmar que todos os atributos analisados apresentaram dependência espacial.

A infiltração e a distribuição das frações granulométricas na área de estudo são diretamente influenciadas pelo relevo da encosta.

Houve uma relação muito clara entre a infiltração e os demais atributos físicos do solo, observando essa correlação principalmente na parte de maior altitude da encosta.

A dinâmica do processo de degradação da área de encosta pode ser mais bem compreendida através da análise espacial dos atributos físicos do solo.

\section{AGRADECIMENTOS}

À Coordenação de Aperfeiçoamento de Pessoal de Nível Superior (Capes) pela concessão da bolsa de estudo.

\section{REFERÊNCIAS}

ARTUR, A. G. et al. Variabilidade espacial dos atributos químicos do solo, associada ao microrrelevo. Revista Brasileira de Engenharia Agrícola e Ambiental, Campina Grande, v. 18, n. 2, p. 141149,2014

ANTONELI, V.; THOMAZ, E. L. Comparação de infiltração de água no solo mensurada em período seco e úmido, em diferentes usos da terra na bacia do arroio Boa Vista, Guamiranga, Paraná. Ambiência, Guarapuava, v. 5, n. 2, p. 301-317, 2009.

BETIOLI JÚNIOR, E. et al. Intervalo hídrico ótimo e grau de compactação de um Latossolo Vermelho após 30 anos sob plantio direto. Revista Brasileira de Ciência do Solo, Viçosa, v. 36, n. 3, p. 971-982, 2012 .

BRASIL. Ministério da Agricultura. Escritório de Pesquisas e Experimentação. Equipe de Pedologia e Fertilidade do Solo. Levantamento exploratório reconhecimento de solos do Estado da Paraíba. 
Rio de Janeiro-RJ, 1972. 670 p.

CAMARGO, L. A.; MARQUES JÚNIOR, J.; PEREIRA, G. T. Spatial variability of physical attributes of an alfisol under different hillslope curvatures. Revista Brasileira de Ciência do Solo, Viçosa, v. 34, n. 3, p. 617-630, 2010.

CAMBARDELLA, C. A. et al. Field scale variability of soil properties in Central Iowa soils. Soil Science Society of America Journal, Madison, v. 58, n. 5, p. 1501-1511, 1994.

CAMPOS, M. C. C. et al. Bergamin, A. Cristian. Variabilidade espacial dos atributos físicos em um Argissolo Vermelho sob floresta. Comunicata Scientiae, Bom Jesus-PI, v.4, n.2, p. 168-178, 2013.

CAMPOS, M. C. C. et al. Variabilidade espacial da resistência do solo à penetração e umidade em áreas cultivadas com mandioca na região de Humaitá, AM. RevistaAgro@mbiente On-line, Boa Vista, v. 6, n. 1, p .09-16, 2012.

CARVAlHO, L. A. de. et al. Dependência espacial dos atributos físicos de três classes de solos cultivados com cana-de-açúcar sob colheita mecanizada. Revista Brasileira de Engenharia Agrícola e Ambiental, Campina Grande, v. 15, n. 9, p. 940-949, 2011.

EMBRAPA. Manual de análises químicas de solos, plantas e fertilizantes. 2. ed. Brasília, DF: Centro nacional de Pesquisa de Solos, Informação Tecnológica, 2009. $628 \mathrm{p}$

EMPRESA BRASILEIRA DE PESQUISA AGROPECUÁRIA - EMBRAPA. Manual de análises químicas de solos, plantas e fertilizantes. 2.ed. Brasília, Informação Tecnológica, 2009. 628p.

GAMMA DESIGN SOFTWARE (GS+). Geostatistics for the environmental sciences. 7. ed. Plainwell: Gamma Design, 2004.

GOLDEN SOFTWARE. Surfer versão 9. Tutorial. User's guide, 2010.

GALVÃO, S. R. S.; SALCEDO, I. H.; SANTOS, A.C. Frações de carbono e nitrogênio em função da textura, do relevo e do uso do solo na microbacia do agreste em Vaca Brava (PB). Revista Brasileira Ciência do Solo, Viçosa, v. 29, n. 2, p. 955-962, 2005.

GUEDES FILHO, O. et al. Saptial and temporal variability of crop yield and Rhodic Hapluodox properties underno-tillage. Revista Brasileira de Ciência do Solo, Viçosa, v. 34, n. 2, p. 1-14, 2010.
JOSÉ, J. V. et al. Variabilidade espacial de variáveis físico-hídricas de dois Latossolos da região noroeste do estado do Paraná. Irriga, Botucatu, v. 17, n. 2, p. 208-219, 2012.

LASSABATÈRE, L. et al. Beerkan estimation of soil transfer parameters through infiltration experiments - BEST. Soil Science Society of American Journal, Madison, v. 70, n. 2, p. 521-532, 2006.

MION, R. L. et al. Variabilidade espacial da porosidade total, umidade e resistência do solo à penetração de um Argissolo amarelo. Semina, Londrina, v. 33, n. 6, p. $2057-2066,2012$.

OLIVEIRA, D. P. de. et al. Microrrelevo e a distribuição de frações granulométricas em Cambissolos de origem calcária. Revista Ciência Agronômica, Fortaleza, v. 44, n. 4, p. 676-684, 2013.

SANTOS, H. G. et al. Sistema brasileiro de classificação de solos. 2. ed. Rio de Janeiro, RJ: EMBRAPA SOLOS, 2006. 306 p.

SANTOS, K. S. et al. Variabilidade espacial de atributos físicos em solos de vale aluvial no semiárido de Pernambuco. Revista Brasileira de Engenharia Agrícola e Ambiental, Campina Grande, v. 16, n. 8, p. $828-835,2012$.

SILVA, F. de A. S.; AZEVEDO, C. A. V. de. Versão do programa computacional assistat para o sistema operacional Windows. Revista Brasileira de Produtos Agroindustriais, Campina Grande, v. 4, n. 1, p. 71-78, 2002.

SIQUEIRA, G. M.; VIEIRA, S. R.; CEDDIA, M. B. Variabilidade espacial de atributos físicos do solo determinados por métodos diversos. Bragantia, Campinas, v. 67, n. 2, p. 693-699, 2008.

SOUZA, M. D. de. et al. Atributos físicos e químicos de área degradada tratada com lodo de esgoto. 1. ed. Jaguariúna: Embrapa Meio Ambiente, 2011.6 p. (Circular técnica, 21).

SOUZA, E. S. de. et al. Caracterização hidrodinâmica de solos: Aplicação do método Beerkan. Revista Brasileira de Engenharia Agrícola e Ambiental, Campina Grande, v. 12, n. 2, p. 128-135, 2008.

SOUZA, Z. M. de. et al. Small relief shape variantions influence spatial variability of soils chemical attributes. Scientia Agricola, Piracicaba, v. 63, n. 2, p. 161-168, 2006.

TAVARES, U. E. et al. Variabilidade espacial de atributos físicos e mecânicos de um Argissolo sob cultivo de cana-de-açúcar. Revista Brasileira de Engenharia Agrícola e Ambiental, Campina Gran- 
de, v. 16, n. 11, p. 1206-1214, 2012.

TORRES, J. L. R. et al. Resistência à penetração em área de pastagem de capim Tifton, influenciada pelo pisoteio e irrigação. Biosciece Journal. Uberlândia, v. 28, n. 1 , p. 232-239, 2012.

TRANGMAR, B. B. et al. Applications of geostatistics to spatial studies of soil properties. Advances in Agronomy, San Diego, v. 38, n. 1, p. 45-94, 1985.

VIEIRA, S. R. Geoestatística em estudos de variabilidade espacial do solo. In: NOVAIS, R. F.; ALVARES, V. H.; SCHAEFER, C. E. G. R. (Ed.). Tópicos em Ciência do Solo. Viçosa: Sociedade Brasileira de Ciência do Solo, 2000. v. 1, cap. 6, p. 1 -54 .

WARRICK, A.W.; NIELSEN, D. R. Spatial variability of soil physical properties in the field. In: Hillel, D. (Ed.). Applications of soil physics. New York: Academic, 1980. cap. 2, p. 319-344. 